\title{
LIST OF LETTERS AND POSTCARDS
}

\begin{tabular}{|c|c|c|c|c|}
\hline & Date & Autbor & Written from & Page \\
\hline I. & August 10, 1855 & Butler & Cambridge & 35 \\
\hline 2. & February 5,1857 & Butler & Cambridge & 36 \\
\hline 3. & September 27,1859 & Butler & London & 38 \\
\hline 4. & [ca. March 21, 186I] & Butler & [New Zealand] & 41 \\
\hline$s$. & September 24,1866 & Butler & London & 42 \\
\hline 6. & October 4,1866 & Butler & [London] & 43 \\
\hline 7. & January 30,1867 & Butler & London & 45 \\
\hline 8. & August 30,1868 & Butler & London & 46 \\
\hline 9. & July 4, [1869] & Butler & London & 48 \\
\hline to. & March 20, 1870 & Butler & Venice & 50 \\
\hline II. & [July, 1870] & Butler & London & 33 \\
\hline 12. & July $8, \quad 1872$ & May & [Langar] & 54 \\
\hline 3. & February 23,1873 & Butler & [London] & 56 \\
\hline ז4. & March 2, 1873 & May & Mentone, [France] & 58 \\
\hline is. & March 12, 1873 & Butler & London & 60 \\
\hline : 6. & March 24, $[1873]$ & Butler & London & 61 \\
\hline 7. & August S, 1873 & Butler & London & 63 \\
\hline 18. & November 12,1873 & Butler & London & 65 \\
\hline 59. & June 20, [1874] & Butler & $\begin{array}{l}\text { [En route to } \\
\text { Montreal] }\end{array}$ & 66 \\
\hline 20. & August 13,1875 & Butler & $\begin{array}{l}\text { [En route to } \\
\text { Montreal] }\end{array}$ & 67 \\
\hline & June 2, 1876 & Butler & Faido, [Switzerland] & 68 \\
\hline 22. & March 27, 1878 & Butler & London & 69 \\
\hline 23. & July 22,1878 & Butler & Faido, Swizzerland & $7 x$ \\
\hline 24. & October 21,1878 & Butler & London & 73 \\
\hline & January 18,1879 & Butler & London & 74 \\
\hline
\end{tabular}




\section{Date}

26. February 11, 1879

27. March 14, 1879

28. July 31,1879

29. August 21,1879

30. March 12, 1880

31. May 3, 1880

32. June 10,1880

33. June 29, 1880

34. July 16,1880

35. November 22,1880

36. February 27, 1881

37. April 22, 188 I

38. December 10, 188 I

39. December 17, 1881

40. March 4, 1882

41. August 30,1882

42. March 19, 1883

43. March 29, I88 3

44. September $11,[1883]$

45. September 12,1883

46. November 1,1883

47. December 6, [1883]

48. December 24, 1883

49. January 9, 1884

so. January 16,1884

51. January 20, 1884

52. [February 1,1884 ]

33. February 12, 1884

34. February 22, 1884

is. April 9, 1884

56. May S, 1884

57. May I3, $188_{4}$

58. May 29, 1884

59. June 20, 1884

60. August 6, [1884]

61. September 7,1884

62. December 20, 1884

63. December 30, 1884

64. February 1, 188,

65. March 4, 188 s

66. April 2, 1885

67. April I , 188 ,

68. June 30,188 ,

\section{Autbor}

Butler

Butler

May

Butler

May

Butler

Butler

Butler

Butler

Butler

May

Butler

May

Butler

May

Butler

Butler

Butler

May

Butler

May

May

May

Butler

Butler

Butlet

Butler

Butler

Butler

Butler

Butler

Butler

Butler

Bucler

Butler

Burler

Butler

Butler

May

Butler

Butler

Butler

Butler
Written from

Page

London

London

Nottingham

Mesocco,

Switzerland

Shrewabury

London

London

London

Sant' Ambrogio,

Italy

London

Shrewsbury

[London]

[Shrewsbury]

London

Shrewsbury

Aosta, [Italy ]

London

London

Shrewsbury

London

Shrewsbury

[Shrewsbury]

Shrewsbury

London

London

[London]

London

London

London

London

London

London

London

London

London

Soglio,

[Sritzerland]

London

London

Shrewsbury

London

London

London

London 
Date

69. July 24, 188,

70. August 23, 1885

71. September $9,188 \mathrm{~s}$

72. October 12, 188 s

73. October 21, [188, ]

74. December 22, 1885

75. December 29, 188 ,

76. January 18, 1886

77. March 24, 1886

78. May 27, 1886

79. June 3, 1886

80. July 21,1886

81. [August, 1886]

82. September 9, 1886

83. September 13,1886

84. October I, 1886

85. October 2, 1886

86. October 10, 1886

87. October 19, 1886

88. October 30, 1886

89. November 4,1886

90. November 9, 1886

91. November 10, [1886]

91. [November 30, 1886]

93. November 30,1886

94. December 1, 1886

95. [Morning,]

December 1, [1886]

96. [Evening,]

December $x, 1886$

97. December 2, 1886

98. [December 4, 1886]

99. December 7, 1886

100. December 8, 1886

ror. December 8, 1886

102. December II, 1886

103. December 12,1886

104. December 13, [1886]

105. December 16, 1886

106. [December 21, 1886]

107. December 23, 1886

108. March 27, 1887

109. December 13,1887

I ro. November 12, 1888
Autbor

Butler

Butler

Butler

Butler

Butler

Butler

Butler

Butler

Butler

Butler

Butler

Butler

Butler

Butler

Butler

May

Butler

Butler

Butler

May

Butler

Butler

May

May

Butler

Butler

May

May

Butler

May

May

Bucler

May

May

Butler

May

May

May

Butler

Butler

Butler

Butler
Written from

Page

London

143

Varallo Sesia,

[Italy]

145

Varese, Italy

147

London

149

London

IS 1

London

153

London

154

156

197

159

160

162

164

166

Faido, Switzerland

Bellinzona,

[Switzerland]

167

Shrewsbury

167

169

170

172

174

175

177

178

179

179

180

London

London

181

[Shrewsbury]

182

[Shrewsbury]

183

London

184

184

185

186

186

187

189

190

191

192

193

194

196 


\begin{tabular}{|c|c|c|c|c|}
\hline & Date & Autbor & Written from & Page \\
\hline III. & January 13,1889 & Butler & London & 197 \\
\hline I 12. & July 1, 1889 & Butler & [London] & 199 \\
\hline 113. & March 6, 1890 & Butler & London & 201 \\
\hline 114. & September 18,1890 & Butler & Carate, [Italy] & 203 \\
\hline IIs. & February 14,1891 & Butler & London & 205 \\
\hline I 16. & [Mid-August, $189 \mathrm{I}$ ] & Butler & Bormio, Italy & 207 \\
\hline II7. & September 30,1891 & Butler & London & 209 \\
\hline 118. & January 18,1892 & Burler & London & 210 \\
\hline 119. & February 27,1892 & Butler & London & 212 \\
\hline I 20. & April 25, 1892 & May & Shrewsbury & 213 \\
\hline 121. & April 26,1892 & Butler & [London] & 214 \\
\hline 122. & $\mathrm{May}_{22}, 1892$ & Butler & London & 216 \\
\hline 123. & June 18,1892 & Butler & London & 218 \\
\hline 124. & August 10,1894 & Butler & Trapani, [Italy] & 219 \\
\hline 125. & January 25, 1895 & May & [Shrewsbury] & 220 \\
\hline 126. & March Is, 189s & Butler & London & 221 \\
\hline 127. & November 26,1895 & May & Shrewsbury & 222 \\
\hline 128. & April 28,1897 & May & Shrewsbury & 224 \\
\hline 129. & [May 24, 1897] & May & Shrewsbury & 225 \\
\hline 130. & June 17,1897 & May & Shrewsbury & 226 \\
\hline $13 \pi$. & October 26, [1898] & Butler & London & 227 \\
\hline 132. & January 4, [1899] & Butler & [London] & 227 \\
\hline 133. & January s, 1899 & May & [Shrewsbury] & 229 \\
\hline 134. & May IS, [1899] & Butler & Verona & 230 \\
\hline 135. & June 26,1899 & May & Shere, [England] & 231 \\
\hline 136. & July 24, 1899 & Butler & London & 232 \\
\hline I37. & October 10, 1899 & May & Shrewsbury & 234 \\
\hline I38. & April 26, 1900 & Butler & Taormina, Sicily & 235 \\
\hline 139. & May 6, 1900 & Butler & Malta & 236 \\
\hline 140. & June $3,[1900]$ & Butler & Sant' Ambrogio, & \\
\hline & & & & 237 \\
\hline $\begin{array}{l}141 . \\
142 .\end{array}$ & $\begin{array}{l}\text { July 2, [1900] } \\
\text { October } 24,1900\end{array}$ & $\begin{array}{l}\text { May } \\
\text { May }\end{array}$ & $\begin{array}{l}\text { [Shrewsbury] } \\
\text { Shrewsbury }\end{array}$ & 237 \\
\hline $\begin{array}{l}142 . \\
143 .\end{array}$ & $\begin{array}{l}\text { October } 24,1900 \\
\text { February }\end{array}$ & May & & 238 \\
\hline 143. & February S, [1901] & May & [Shrewsbury] & 239 \\
\hline 144. & October 21, 1901 & Butler & London & 240 \\
\hline 145 & January $6,[1902]$ & Butler & London & 240 \\
\hline 146. & February 17,1902 & May & Shrewsbury & 241 \\
\hline 147. & April 17, [1901] & Butler & Palermo & 243 \\
\hline 148. & April I8, 1902 & Butler & Palermo & 244 \\
\hline 149. & April 19, [1902] & Butler & Palermo & 245 \\
\hline I so. & April 21, [1902] & Butler & Palermo & 245 \\
\hline I5x. & April 21, [1902] & Butler & Palermo & 246 \\
\hline Is2. & May 14, [1902] & Butler & Naples & 246 \\
\hline I53. & May 16, 1902 & Butler & Naples & 247 \\
\hline
\end{tabular}

